\title{
PEMBELAJARAN FISIKA BERBANTUAN KOMPUTER INTERAKTIF (PFBPKI) SEBAGAI SELF OPERATED INSTRUMENT (SOI), DAN PFBPKI SEBAGAI MEDIA, SERTA PEMBELAJARAN TANPA BANTUAN KOMPUTER
}

\author{
Festiyed $^{*}$ \\ Jurusan Fisika FMIPA UNP Padang \\ E-mail festiyed@yahoo.com
}

\begin{abstract}
The aim of this study was to investigate the improvement of the students' attention after using there different methods of HICAI-SOI, HICAI-Media, and with out CAI three exell-1, exell-2 and regularly class.The research method was Quasi-experiment. The sample of the research were 90 persons from class VIII Junior High School Students 7 Padang, that was selected randomly. Prior knowledge of student as bilinear covariant is obtained through cognitive domain test and attention score of learning is collected through questionnaire. The validity and reability of both instrument were tested, and the coefficient 0,83 and 0,92 . Result of examination applies bilinear covariant analyst technique (ANACOVA) factorial $3 \times 3 \times 1$, successfully controls initial ability equal to $67 \%$. Attention of student learning increases in signifikan from study trivariable, to three treatment classes $[\mathrm{F}(2,253)=183,92, \mathrm{p}<0,05]$ with effect size equal to $59 \%$, difference of class to attention also highly significant $[\mathrm{F}(2,253)=8,39, \mathrm{p}<0,05]$ with effect size equal to $6 \%$, medium of interaction influence between various studies with class also highly signifikan $[\mathrm{F}(2,253)=8,39, \mathrm{p}<0,05]$ with effect size equal to $7 \%$.Result of analysis shows the contribution of various study to increase attention of far bigger than difference of class and interaction. Therefore, the conjecture of the writer that the attention influences learning process in provable emperical. This research showed that the student Junior High School Students is more interested to study physics with HICAI-SOI. Its gives more impact on the students' attention at regular class, It is concluded that the use of HICAI can improve the attention of Junior High School Students.
\end{abstract}

Key Words: attention, Computer Assested Instruction,

\footnotetext{
${ }^{*}$ Dosen Jurusan Fisika FMIPA Universitas Negeri Padang
} 


\section{PENDAHULUAN}

Pembelajaran bertujuan agar peserta didik menjadi pribadi dewasa yang matang dan mapan sehingga mampu menghadapi berbagai masalah dan konflik dalam kehidupan sehari-hari. Agar tujuan ini dapat tercapai maka diperlukan sistem pembelajaran yang aktif, inovatif, kreatif, efektif dan menyenangkan ( PAIKEM joyful learning) yang bercirikan: Multi metode, multi model, multi media; Praktek dan bekerja dalam tim; Memanfaatkan lingkungan sekitar; Di dalam dan di luar kelas; Multiaspek (logika, praktika, etika); Hasil Belajar utuh (kognitif, afektif, dan psikomotorik)

Namun kenyataannya kebanyakan pendidik belum memberdayakan seluruh potensi dirinya, belum dapat menyediakan pengalaman belajar untuk peserta didiknya yang beragam baik mental, fisik dan sosial sebagai guru yang PAIKEM. Guru masih banyak terjebak dalam praktek kegiatan belajar mengajar yang cenderung membosankan dan tidak inovatif bahkan membuat peserta didik menjadi tertekan. Begitu juga dalam berinteraksi dengan peserta didik, posisi guru terasa masih sangat dominan, sementara peserta didik cenderung berada dalam posisi yang tidak berdaya. Pendekatan dan metode yang digunakan tampak kurang bervariasi, biasanya kebanyakan mengandalkan ceramah, belum banyak menggunakan berbagai alat bantu dan cara membangkitkan semangat (Aljufri, Festiyed dan Syakbaniah, 2009). Guru juga belum mengoptimalkan lingkungan sebagai sumber belajar untuk menjadikan pembelajaran menarik perhatian, menyenangkan, dan cocok bagi peserta didik. Konsep kegiatan pembelajaran seperti itu tidak relevan lagi dengan tuntutan dan tantangan pendidikan di era globalisasi (Festiyed, 2008).

Pada era globalisasi suasana kehidupan semakin rumit "complicated", cepat berubah dan sulit diprediksi "unpredictable", (Gunaryadi, 2004), dan ilmu berkembang dengan cepat tetapi manusia yang mempelajarinya tetap (Aljufri B.Syarif, 2007). Degeng (1998) menyatakan bahwa kita telah memasuki era kesemrawutan, dimana era ini tidak dapat dijawab dengan paradigma keteraturan, kepastian, dan ketertiban. Tetapi harus dijawab dengan paradigma kesemrawutan. Era kesemrawutan ini dilandasi oleh teori dan konsep konstruktivistik; suatu teori 
pembelajaran yang kini banyak dianut di kalangan pendidikan di AS. Unsur terpenting dalam konstruktivistik adalah kebebasan dan keberagaman. Kebebasan yang dimaksud ialah kebebasan untuk melakukan pilihan-pilihan sesuai dengan apa yang mampu dan mau dilakukan oleh peserta didik. Keberagaman adalah peserta didik menyadari bahwa individunya berbeda dengan orang/kelompok lain, dan orang/kelompok lain berbeda dengan individunya.

Kenyataan di lapangan untuk pembelajaran fisika berdasarkan hasil survey penulis ke beberapa Sekolah Menengah Pertama (SMP) di Padang (2006), dapat disimpulkan, peserta didik diberlakukan sama, sehinggga banyak peserta didik merasa bosan dan kurang tertarik belajar, serta berharap jam pelajaran fisika cepat usai. Penelitian Hamdi dan Festiyed (2001:3):" Siswa cendrung punya persepsi bahwa fisika adalah pelajaran yang kurang menarik perhatian, penuh dengan hitungan seperti matematika, rumus-rumus yang harus dihapal serta kurang adanya aplikasi pelajaran dalam kehidupan sehari-hari". Hasil-hasil evaluasi belajar pun menunjukkan bahwa nilai rata-rata kelas untuk pelajaran fisika seringkali merupakan nilai yang terendah di banding dengan pelajaran-pelajaran lain

Gangguan perhatian dalam belajar tidak hanya disebabkan sulitnya mata pelajaran fisika, juga disebabkan periodisasi siswa dalam kehidupan. Siswa SMP dikatakan berada dalam masa prapubertas pueral atau berada dalam masa kanakkanak akhir dengan ciri-ciri utamanya adalah: anak dalam keadaan kurang tenang; pikiran, perasaan dan keinginannya selalu berubah-ubah dan cepat merasa bosan; sering memberanikan diri untuk mengerjakan sesuatu tanpa berpikir panjang; meragukan pengetahuan dan kemampuannya sendiri; perhatian terhadap lingkungannya dan terhadap pelajaran di sekolah berkurang; dan sangat mudah terkena pengaruh teman-teman sebaya yang kurang baik. Pada masa anak di SMP dan SMA tugas pendidik menjadi lebih berat, pendidik dituntut mampu memahami tahap perkembangan anak yang cepat bosan dan berkurangnya perhatian terhadap pelajaran (Susilowindradini,1993).

Menarik perhatian siswa untuk belajar di zaman teknologi informasi yang serba cepat berubah ini tidaklah mudah. Tetapi mengapa banyak siswa tak jemu untuk berlama-lama di depan sebuah episode sinetron yang ditayangkan televisi? Juga 
betapa hebohnya daya gugah iklan di televisi? Hal itu disebabkan tayangan tersebut dikemas sebegitu canggih dan menarik perhatian dengan memanfaatkan keunggulan multimedia. Di satu sisi, zaman memberikan berbagai banyak kemajuan teknologi yang memungkinkan anak-anak memperoleh fasilitas yang serba "canggih". Di sisi lain, pembelajaran di sekolah belum seiring dengan perkembangan teknologi tersebut dan peralatan laboratorium dan sumber daya pengelolanya belum tersedia serta guru belum terbiasa dengan model pembelajaran yang tanggap terhadap perubahan ilmu dan teknologi yang begitu cepat.

Cukup banyak orang tua yang merasa khawatir karena anaknya telah kehilangan motivasi dalam belajar. Apalagi pada era globalisasi seperti sekarang ini, jenis permainan yang menarik sangat banyak diproduksi. Anak kehilangan perhatian pada pelajaran, karena dalam pikirannya masih teringat permainan yang baru selesai dimainkannya (Popy Yaniawati, 2007). Kehilangan perhatian pada pelajaran tersebut, karena gangguan lingkungan lebih menarik dari pelajaran. Walau hadirnya komputer dapat diprogram agar pembelajaran menarik namun perancangannya memerlukan keahlian programmer, ahli desain dan ahli pendidikan.

Kehadiran teknologi komputer yang dapat digunakan dalam pendidikan, diharapkan sebagai solusi untuk mengatasi kendala yang dihadapi dunia pendidikan. Hal ini didukung oleh: pertama masyarakat sudah banyak yang memiliki komputer sendiri, maka memungkinkan dikembangkannya paket belajar personal interaktif yang unik dan menarik perhatian. Paket ini dapat berupa: Computer Assisted Instructional (CAI) atau Computer Based Training (CBT) dan lainnya. Kedua, proses penyampain materi ajar yang akan ditransformasikan dapat lebih efektif dan efisien. Untuk ini diperlukan guru yang professional, aktif, kreatif dan mampu melakukan inovasi dalam pembelajaran. Guru diharapkan mampu memanfaatkan kelebihan yang yang dimiliki komputer untuk pembelajaran.

Gagne (1985), menjelaskan pembelajaran terdiri dari tiga komponen, yaitu kondisi eksternal, kondisi internal, dan hasil belajar. Komponen ini dapat dilihat pada Gambar 1, bahwa belajar merupakan: (a) interaksi antara "keadaan internal dan proses kognitif siswa" dengan "stimulus dari lingkungan", (b) proses kognitif tersebut menghasilkan suatu hasil belajar. Hasil belajar terdiri dari informasi verbal yaitu 
kapabilitas untuk mengungkapkan pengetahuan dalam bentuk bahasa baik lisan maupun tertulis, ketrampilan intelek yaitu kecakapan yang berfungsi untuk berhubungan dengan lingkungan hidup serta mempresentasikan konsep dan lambang, strategi kognitif yaitu kemampuan menyalurkan dan mengarahkan aktivitas kognitifnya sendiri, ketrampilan motorik yaitu kemampuan melakukan serangkaian gerak jasmani dalam urusan dan koordinasi, dan sikap yaitu kemampuan menerima atau menolak objek berdasarkan penilaian terhadap objek tersebut.

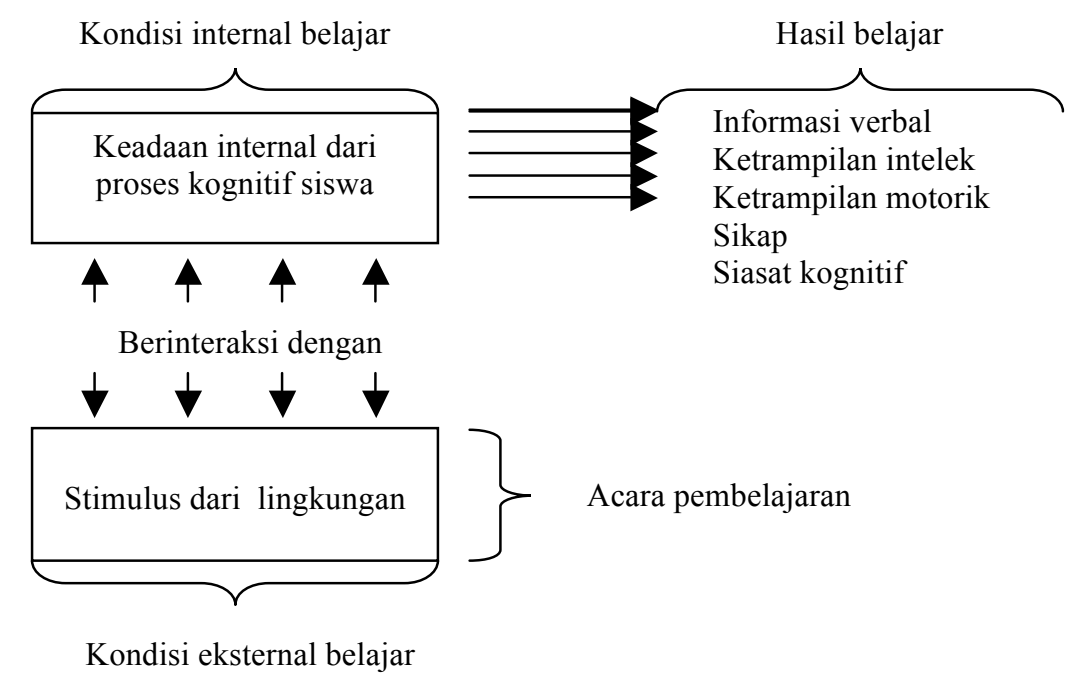

Gambar 1. Komponen Esensial Belajar dan Pembelajaran (Adaptasi: Bell Gredler, 1991:188, dalam Dimyati dan Mujiono1999:11).

Membuat acara pembelajaran merupakan stimulus dari lingkungan yang dapat diusahakan oleh guru sebagai variasi pembelajaran untuk menarik perhatian siswa.

Menurut teori belajar kognitif sosial, belajar dapat terjadi melalui pengamatan model dan sebagai pengamat membayangkan seolah-olah mengalami sendiri apa yang dialami model. Adapun yang disebut model adalah sesuatu yang perilakunya dipelajari dan atau ditiru oarang lain. Menurut Bandura (1977), ada empat fase belajar dari model adalah: (1) attention phase, (2) retention phase, (3) reproduction phase, (4) motivational phase. Jadi berdasarkan teori belajar kognitif sosial perhatian adalah hal yang utama. Begitu juga pada model pemrosesan informasi, perhatian adalah hal yang utama, perhatikan Gambar 2 berikut: 


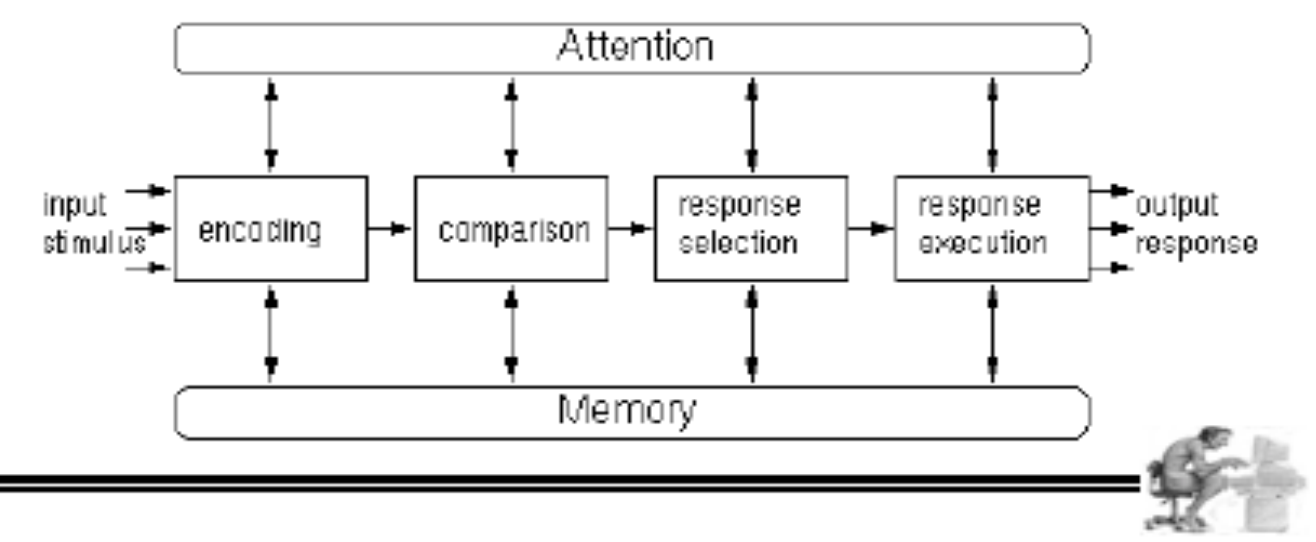

Gambar 2. Tahap Pemrosesan Informasi (Barber,1988; Restyandito,2007)

Tahap pemrosesan informasi yang tersebut mendorong trend pengembangan perangkat lunak sesuai dengan karakteristik individu. Di samping itu juga diperhatikan kemudahan menjalankan program dan kecepatan adaptasi pengguna dalam menjalankan program, atau disebut sebagai aplikasi yang "user friendly". Demikian juga desain Pembelajaran Fisika Berbantuan Program Komputer Interaktif (PFBPKI) bergantung pada perhatian dan kepuasan pemakai. Karena PFBPKI tergantung pada perhatian dan kepuasan pemakai yang lebih bersifat subjektif, maka pada dasarnya tidak ada sebuah desain yang ideal, tetapi yang ada adalah desain yang menarik perhatian dan bermanfaat bagi pengguna. Desain PFBPKI ditekankan pada bagaimana menarik perhatian siswa sebagai pengguna utama.

Penelitian yang berhubungan dengan inovasi pembelajaran dalam memanfaatkan komputer meningkatkan penguasaan konsep dan keterampilan berpikir kreatif siswa pada tingkat sekolah dasar (Kulik,1983; Wiederhold, 1988; Criswell, 1989, dan Schacter, 1999), pada materi fisika tingkat SMP (Kartini, 2004; Nanang Suwondo, 2002, dan Agus Budi Hartono, 2007). Kaitan minat dan perhatian dengan hasil belajar IPA siswa SMP (St.Nurhaedah Nur, 2006). Materi fisika tingkat mahasiswa (Festiyed, 1990, 2000, 2002; Syakbaniah dan Festiyed, 2005) Upaya bagaimana meningkatkan perhatian belajar siswa menggunakan program komputer interaktif merupakan hal yang baru. 
Penggunaan komputer untuk pembelajaran juga didukung oleh tersedianya dipasaran software pendidikan. Beberapa contoh produk software pembelajaran tersebut adalah: Pesona Fisika dan Pesona Matematika untuk SMP, SMA dari Kuantum Inti Dinamika; Belajar Matematika Bersama Mr.Sicerdas untuk SD-SMPSMA dari Wahana Komputer; Software EduGames Maximize Studio untuk tingkat SD; Software Anak Cerdas dari Akal Interaktif; Software Tutorial Komputer dari Bamboo Media; Program Belajar Lebih Menyenangkan dengan CD Animasi Edutama Animasi dan Multimedia, dan lain-lainnya (Festiyed, 2003).

Software yang telah tersedia di pasaran telah didesain dengan memperhatikan efektif dan efesien penggunaan resource komputer, program berjalan dengan baik dan tidak mudah berhenti saat dijalankan; struktur program tersusun sederhana dan mudah dipahami walau menjalankan fungsí yang komplek; pengguna dapat dengan mudah memperkirakan bahkan menentukan relasi antara aksi dan hasil, antara kontrol-kontrol dan efek yang ditimbulkan; pengguna dengan mudah memakai tanpa hambatan spesifikasi hardware dan software yang disyaratkan; proses instalasi mudah; dokumentasi program lengkap. Tetapi belum sepenuhnya sesuai dengan kaidah pendidikan yang sesungguhnya. Misalnya software yang sudah ada pada bagian latihan soal belum memasukkan unsur penguatan dan interaktif serta aspek psikologi siswa.

Penelitian ini memasukkan unsur pendidikan yang belum terdapat pada software yang telah ada dipasaran. Penambahan program bertujuan memodifikasi kesan supaya lebih interaktif, unik, menyenangkan, sehingga membuat pembelajaran menarik perhatian siswa. Penambahan program difokuskan pada bagian soal latihan, dengan pemberian penguatan, memperhatikan aspek psikologi siswa, pengaturan waktu yang disesuaikan dengan tingkat kesulitan soal, keluaran nomor dan option soal secara random, hasil jawaban soal dapat di print dan dikirim melalui e-mail.

Penelitian ini bertujuan mengkaji peningkatan perhatian belajar siswa mengunakan tiga variasi Pembelajaran Fisika Berbantuan Program Komputer Interaktif (PFBPKI) sebagai Self Operated Instrument (SOI), dan PFBPKI sebagai media, serta pembelajaran tanpa PFBPKI pada tiga kelas unggul-1, kelas ungul-2 dan kelas biasa, melalui studi kuasi eksperimen.. 


\section{METODOLOGI}

Desain pada penelitian ini adalah desain kuasi ekperimen (Quasi Experimental Design). Pengolahan data menggunakan teknik analisis kovarian (ANCOVA atau ANACOVA), faktorial $3 \times 3 \times 1$.Pengolahan data menggunakan paket program aplikasi komputer SPSS (Statistical Program for Social Science) for Windows dan ditambah dengan bantuan komputer program excel.

Penelitian dilakukan pada semester genap tahun ajaran 2007/2008, periode Januari-Juni 2008 di SMPN 7 Padang, dengan populasi adalah siswa-siswa seluruh SMPN 7 Padang. Penarikan sampel dilakukan dua tahap, tahap pertama memilih satu tingkatan kelas yaitu kelas VIII dari tiga tingkatan kelas (VII,VIII dan IX) yang akan dijadikan kelas sampel. Tahap kedua memilih kelas perlakuan yang akan dijadikan kelompok eksperiemen-1 yang mewakilli kelas unggul, ekperimen-2 mewakili kelas sedang dan eksperimen-3 mewakili kelas rendah. Pengambilan seperti ini karena di SMPN 7 terdapat kelas unggul-1 lokal, unggul-2 satu lokal dan kelas biasa empat lokal yang terdaftar pada tahun pelajaran 2007/2008, sebanyak 266 orang. Pengambilan tiga buah kelas sampel, dimana kelas unggul-1 sebagai eksperimen-1, unggul-2 sebagai ekperimen-2 secara langsung dan ekperimen-3 dipilih secara random menggunakan fungsi Randbetween $(1,4)$ yang ada pada Microsoft Exel. Diperoleh Siswa yang menjadi sampel sebanyak 90 orang dari kelas VIII. Kemampuan awal siswa sebagai kovarian diperoleh melalui tes aspek kognitif dan data perhatian belajar dikumpulkan melalui kuesioner, kedua instrumen tersebut telah diuji validitas dan koefisien reabilitasnya masing 0.83 dan 0.92 .

\section{HASIL PENELITIAN}

Analisis dilakukan untuk melihat: membandingkan efek perlakuan terhadap variasi pembelajaran dan efek perlakuan terhadap perbedaan kelas. Hasil rangkuman uji hipotesis dapat dilihat pada Tabel 1. 
Tabel 1. Rangkuman Hasil Uji F untuk Perhatian dengan Kovariabel Kemampuan Awal

\begin{tabular}{|l|l|l|l|l|l|l|}
\hline Sumber Variasi & $\begin{array}{l}\text { Jumlah } \\
\text { Kuadrat }\end{array}$ & df & $\begin{array}{l}\text { Mean } \\
\text { Kuadrad }\end{array}$ & F & $\begin{array}{l}\text { P } \\
\text { (Sig.) }\end{array}$ & n2 \\
\hline $\begin{array}{l}\text { Perlakuan } \\
\text { dikoreksi }\end{array}$ & $79,27(\mathrm{~b})$ & 9 & 8,81 & 53,66 & 0,000 & 0,67 \\
\hline $\begin{array}{l}\text { Perbedaan } \\
\text { Kelas }\end{array}$ & 2,76 & 2 & 1,38 & 8,39 & 0,000 & 0,06 \\
\hline $\begin{array}{l}\text { Perbedaan } \\
\text { Metode }\end{array}$ & 60,38 & 2 & 30,19 & 183,92 & 0,000 & 0,59 \\
\hline Kelas * Metode & 3,07 & 4 & 0,77 & 4,67 & 0,001 & 0,07 \\
\hline Kesalahan & 41,53 & 253 & 0,16 & & & \\
\hline Total & 3795,65 & 263 & & & & \\
\hline Total dikoreksi & 120,80 & 262 & & & & \\
\hline
\end{tabular}

Jelas kelihatan pada Tabel 1 bahwa efek utama perbedaan variasi pembelajaran terhadap perhatian siswa sangat signifikan $[F(2,253)=183,92$. $p<0,05$ ] dengan effect size sebesar $59 \%$, dan efek utama perbedaan kelas terhadap perhatian juga sangat signifikan $[F(2,253)=8,39 . p<0,05]$ dengan effect size sebesar $6 \%$, sedang pengaruh interaksi antara variasi pembelajaran dengan kelas juga sangat signifikan $[F(2,253)=8,39$. $p<0,05]$ dengan effect size sebesar $7 \%$. Dari hasil analisis ini menunjukkan sumbangan variasi metode jauh lebih besar dari perbedaan kelas dan interaksi, $59 \%$ dibandingkan dengan $7 \%$ dan $6 \%$. Maka dari itu spekulasi peneliti bahwa perhatian mempengaruhi proses belajar dengan ini secara emperical dapat dibuktikan. Selain dari itu untuk melihat bagaimana learning curve dari ketiga variasi pembelajaran tersebut dilukiskan pada gambar 3 .

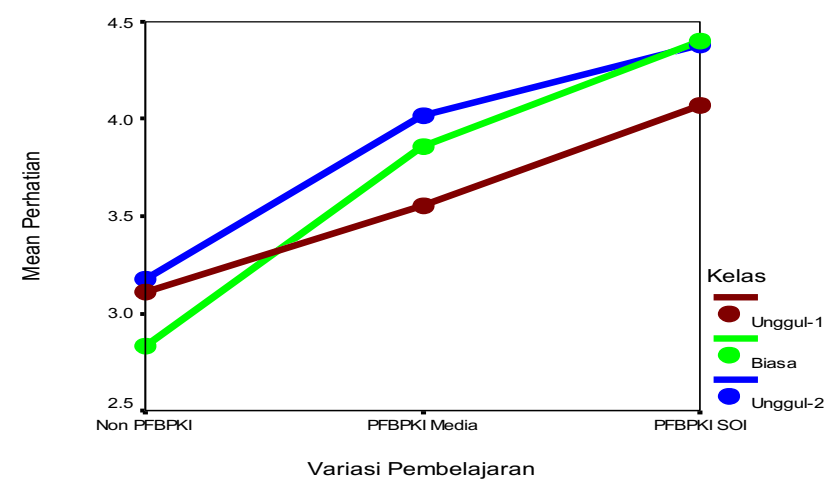


Gambar 3. Mean Perhatian untuk Berbagai Variasi Pembelajaran dan Kelompok Siswa

Dari Gambar 3 ternyata gain skor dari mean perhatian siswa untuk variasi pembelajaran Non-PFBPK pada kelas unggul-2 dan unggul-1 tidak berbeda, tetapi terjadi perbedaan relatif lebih besar pada kelas biasa, artinya selain kovariat kemampuan awal sebagai penetralisisir, ternyata ada faktor lain yang dicurigai mempengaruhi sehingga terjadi perbedaan tersebut. Tetapi walaupun ada faktor lain yang dicurigai, hasil pembelajaran berbantuan program komputer interaktif memberikan sumbangan yang relatif lebih tinggi digunakan pada kelas biasa, diikuti oleh kelas unggul-2 dan kelas unggul-1.

Temuan penelitian ini didukung dari beberapa penelitian yang menggunakan media komputer seperti: Suppes and Morning Star 1969; Atkinson 1968; Hansen Dick and Lippert 1968; Kulik 1983; Wiederhold 1988; Bangert-Drowns 1985; Becker 1990; Bracey 1987; Ehman and Glen 1987; Hasselbring 1984; Kulik, Kulik, and Bangert-Drowns 1985; Okey 1985; Stennet 1985; Swan, Guerrero, and Mitrani 1989, Criswell 1989; Alcalde, Navarro, Marchena \& Ruiz, 1998; Schacter 1999; Kartini 2004; Nanang Suwondo 2002; Agus Budi Hartono 2007; Festiyed 2002; Festiyed dan Syakbaniah 2005. Semua ini menunjukkan bahwa penggunaan komputer untuk meningkatkan perhatian dan juga hasil belajar. Namun penelitian ini belum bisa membuktikan hubungan variasi pembelajaran dengan perhatian, dan perhatian yang tinggilah yang menyebabkan tingginya hasil belajar. Penelitian ini berhasil mengungkapkan perbedaan dan sumbangan variasi pembelajaran terhadap perhatian, dimana makin tinggi perhatian makin menyenangkan suasana belajar. Makin menyenangkan suasana belajar makin banyak siswa menyediakan waktu untuk belajar, menyebabkan hasil belajar meningkat. Hasil temuan ini relevan dengan Lesy Luzyawati (2008), tingginya waktu curah siswa untuk belajar terbukti meningkatkan hasil belajar. Temuan Goodwin (1986) bahwa pemberian perintah-perintah komputer yang bervariasi terhadap anak dapat meningkatkan kemampuan belajar anak. 
Penelitian Alcalde, Navarro, Marchena \& Ruiz, 1998 menggunakan kcmputer "Game performance assessment is possible after each session", untuk siswa SD dan SMP membuktikan bahwa perhatian akan bertambah makin lama siswa berinteraksi dengan komputer. Hal ini selaras dengan hasil penelitian penulis. Walaupun ia melakukan hanya dalam bentuk permainan berarti tidak ada stress sedang yang peneliti lakukan adalah dalam pelajaran formal. Software pembelajaran difokuskan pada pemberian penguatan, tingkat interaktif yang tinggi, memperhatikan aspek psikologi siswa, pengaturan waktu yang disesuaikan dengan tingkat kesulitan soal, keluaran soal random, menekankan pada perhatian dan kepuasan siswa yang lebih bersifat subjektif, atau disebut sebagai aplikasi yang "user friendly". Semua ini membuktikan bahwa perhatian belajar untuk siswa SD dan SMP dapat ditingkatkan, baik di Spanyol dan di Indonesia memberikan hasil yang sama. Setidaknya penelitian ini membuktikan hasil yang sama dengan yang dilakukan di tempat lain.

Seseorang belajar $50 \%$ dari apa yang dibaca, dilihat, dan didengar (Vernon, Gagne). Dibandingkan dengan hasil yang diperoleh dalam penelitian ini, dimana variasi pembelajaran memberikan sumbangan terhadap perhatian belajar siswa sebanyak 59\%. Terdapatnya peningkatan perhatian, dikarenakan siswa belajar dengan bantuan komputer bukan hanya membaca atau mendengar saja tetapi lebih dari itu seperti pendapat Prayitno (2005) belajar bertujuan mengembangkan dimensi manusia dengan perangkat panca dayanya. Pembelajaran berbantuan komputer dapat diprogram untuk meransang panca daya (daya taqwa, cipta, karsa, rasa dan karya) yang dimiliki siswa, sehingga pembelajaran bermakna, disenangi dan menarik perhatian siswa. Temuan Williamson (1995) bahwa 1 jam diskusi dan penggunaan laboratorium komputer perminggunya akan memberi effect size sebesar $56 \%$ dan ini tampaknya sangat berarti dalam peningkatan prestasi siswa

Temuan Dina Utami (2007), keunggulan animasi untuk menarik perhatian siswa dalam belajar akan memperkuat motivasi. Animasi yang 
digunakan akan efektif apabila siswa memiliki kemampuan awal atau pengetahuan awal (prior knowledge) mengenai konsep yang dijelaskan melalui animasi tersebut. Penelitian ini mempertimbangkan efek kemampuan awal terhadap perhatian diperoleh bentuk persamaan liniernya adalah $\mathrm{Y}=2,61+0,02 \mathrm{X}$. (Y perhatian dan $\mathrm{X}$ kemampuan awal).

Pendapat Krathwohl and Bloom (1971) perhatian yang terkontrol dan terseleksi ditandai dengan rasa senang membaca, senang mengerjakan tugas atau soal-soal, senang melihat animasi/simulasi. Perhatian menurut Bandura awal dari empat fasa belajar, dimana: fasa berikutnya adalah, retensi, reproduksi dan motivasi. Pada fasa perhatian, umumnya para siswa memberikan perhatian pada model yang menarik, model yang berhasil, dan model yang dapat menimbulkan minat. Penelitian ini berusaha menciptakan suasana pembelajaran menggunakan bantuan komputer yang didesain menarik perhatian siswa sehingga siswa memusatkan perhatiannya secara penuh pada belajar, karena perhatian merupakan akar dari seluruh fenomena pembelajaran.

Melalui perhatian, akan terseleksi stimulus (Treisman.1964; Kahneman.1964), dan akan terekam dalam bentuk skemata (K.Reed,Stephen. 1982) yang kemudian akan memudahkan penerimaan stimulus baru. Hal ini sama yang dikatakan oleh Bandura, dan Krathwohl and Bloom (1971) yang mengindikasikan bahwa kemampuan siswa akan bertambah. Hasil yang sama ditemukan oleh Aljufri B.Syarif (1985), ability siswa bertambah, makin peka, dan makin mudah menerima tanggapan. Dengan demikian akan cenderung meningkatkan skor belajar siswa. Peristiwa ini dalam psychology dikenal dengan ability (kemampuan anak dalam belajar akan bertambah).

Pembelajaran berbantuan komputer dapat menghemat waktu di kelas, mudah menampilkan contoh-contoh yang ada dalam kehidupan sehari-hari, dapat dikemas lebih interaktif dan menarik perhatian karena bentuk dan warna bisa dimainkan sesuai kecenderungan bentuk dan warna yang disukai siswa, siswa akan mempunyai waktu untuk mengulang atau melanjutkan ke 
yang lebih tinggi, artinya siswa dapat berkreasi dan akhirnya dapat menemukan cara baru dalam belajar. Dengan demikian perhatian dapat meningkatkan kreatifitas siswa, terbukti dalam penelitian gain skor PFBPKI sebagai SOI relatif tinggi dibanding Non-PFBPKI.

\section{KEPUSTAKAAN}

Aljufri, Festiyed dan Syakbaniah (2009)Studi Peningkatan Kemampuan Tenaga Pendidik dalam Mengimplementasikan Kurikulum Tingkat Satuan Pendikan Sekolah Menengah di Kota Padang Sumatera Barat

Alcalde, Navarro, Marchena \& Ruiz,( 1998). How to Increase Attention Using Assisted Teaching Procedure (http://www.icte.org/T01_144.pdf, diakses 20 Mai 2008)

Agus Budi Hartono (2007). Menyertakan Lingkungan dan Memanfaatkan Multimedia Agar Minat dan Prestasi Belajar Matematika Meningkat (http://p4tkmatematika.com, diakses 5 Maret 2008)

A Styles.Elizabeth.(2005).The Psychology of Attention. The Taylor\& Francis e-Library Aree Witoelar.(2003). Quantum Penyelamat Computer? (University of Groningen) (www.jf.hfi.fisika.net, diakses 28 Juni 2006)

De Porter, Bobbi \& Mike Hernacki, Quantum Learning, Membiasakan Belajar Nyaman dan Menyenangkan, KAIFA Bandung, 1999.

Dick, Walter \& Carey, L. (1985). The Systematic Design of Instruction. California Scoot, Foresman and Company.

Dimyati dan Mujiono (1999). Belajar dan Pembelajaran. Jakarta: Rinek Cipta

Dina Utami (2007), Animasi Dalam Pembelajaran, Makalah Disampaikan pada Seminar Pengembangan IImu Pendidikan, Sabtu, 3 Maret 2007 di Aula Registrasi UNY.

Hamdi, Festiyed.(2001).Studi tentang Penggunaan Metode Quantum Learning (QL) sebagai Alternatif Pengajaran Fisika di SMU Kota Padang. Penelitian. Dikti Jakarta

Festiyed, Syakbaniah (2002). Upaya Meningkatkan Kualitas Pembelajaran Mata Kuliah Gelombang dan Optik melalui Computer Simulated Experiment (CSE) di Jurusan Fisika FMIPA UNP Padang Penelitian. Dikti Jakarta

Festiyed. (2002). Upaya Meningkatkan Kualitas Pembelajaran Mata Kuliah Gelombang dan Optik melalui Computer Simulated Experiment (CSE) di Jurusan Fisika FMIPA UNP Padang. Penelitian. Dikti Jakarta

Festiyed. (2003). Perangkat lunak Interaktif Untuk Evaluasi Fisika dasar: Dampaknya Terhadap Aktivitas Belajar Mahasiswa. Buletin Pembelajaran

Festiyed, Ernawati (2007). Pelajaran Fisika dengan Model PBI di Kelas VIII.3 SMP N 7 Padang. Buletin Pembelajaran

Festiyed, Murtiani (2007). Pengembangan Perangkat Pembelajaran Fisika Berorientasi Life Skill Untuk Meningkatkan Kecakapan Generik (Generic Life Skill). Penelitian. Hibah A2 UNP Padang

Festiyed, Syakbaniah (2008)Model Pembelajaran Integrsi E-Learning berbentuk CD-Multimedia dengan pembelajaran Berorientasi Life Skill untuk Meningkatkan Proses Sains Fisika (Studi Eksperimen di SMPN 12 Padang) ). Hibah A2 UNP Padang

G. Cochran, William.(1991).Teknik Penarikan Sampel (Penerjemah Rudiansyah dan Erwin R.Osman). Jakarta: UI-Press.

Gagne, R.M.(1986). Instructional Tecnology: Foundation. Hillsdale: Lawrence ErImaum Associates, Publishers. 
Grady,M.Tim and Jane D.Grawronski (1983). Computers in Curriculum and Instruction.. San Diego County Departement of Education

Gunaryadi (2004). Pendidikan Nasional, Globalisasi, Dan Peranan

Keluarga.disampaikan dalam seminar dalam rangka peringatan Hari Pendidikan Nasional dan Hari Kebangkitan Nasional, dengan tema umum:"Dunia Pendidikan Indonesia di Tengah Arus Globalisasi: Tantangan, Harapan dan Ketidakpastian," yang diselenggarakan oleh Persatuan Pelajar Indonesia (PPI) Wageningen, 29 Mei 2004, di Alterra Building,Wageningen University, Nederland.

Hamdi dan Festiyed,(2001). Studi Tentang Penggunaan Metode Quantum Learning (QL) sebagai alternatif Pengajaran Fisika di SMU Kota Padang, Laporan Penelitian Proyek Doe-Like UNP

Kartimi (2006). Pengembangan Model Pembelajaran Interaktif Berbasis Komputer Untuk Bahan Kajian Partikel-partikel Materi Sebagai Wahana Pendidikan Siswa SLTP (http://pps.upi.edu/org/abstrakthesis/abstrakipa/abstrakipa04.html, diakses 7 Desember 2006).

Kerlinger, Fred.N.(2006) Foundation of Behavioral Research Third Edition (Terjemahan) Gajah Mada University Press.

Kearsley, G. (1994a). Conditions of learning (R. Gagne Online). (http://www.gwu.edu/ tip/gagne.html diakses 25 Agustus 2007)

Kearsley, G. (1994c). Social learning theory (A. Bandura Online). (http://www.gwu.edu/ tip/bandura.html diakses 25 Agustus 2007)

K.Kirk, Roger. (1982). Experimental Design: Procedures for the Behavioral Sciences Second Edition. Monterey California: Brooks/Cole Publishing Company

K.Reed, Stephen. (1982). Cognition: Theory and Applications. Monterey California: Brooks/Cole Publishing Company

Krathwohl. Davi.R. and Bloom. Benjamin.S., (1971). Taxonomy of Educational Objectives, The Classification of Educational Goals.New York: David McKay Company. INC

Kulik, J. A.; Bangert, R. L.; and Williams, G. W. (1983). Effects of Computer-Based Teaching on Secondary School Students Journal of Educational Psychology

Popy Yuniawati (2007) Peran "E-Learning" Dalam Pembelajaran http://www.pikiranrakyat.com/cetak/2007/042007/12/0902.htm

Prayitno. M.Anyar. Aljufri B.Syarif. (2006). Studi Pengembangan Aplikasi Hight-Touch dan High-Tech dalam Proses Pembelajaran di Sekolah. Laporan Penelitian Hibah Pasca Sarjana-HPTP III. Program Pasca Sarjana UNP.

Syakbaniah dan Festiyed .(2005). Integrasi E-learning dalam Pembelajaran Sistem tutorial untuk meningkatkan Penguasaan konsep dan aktifitas Mahasiswa dalam Perkuliahan Fisika Matematika . Laporan Penelitian. PPKP RII Jakarta 